\title{
Promotion of spinosad biosynthesis by chromosomal integration of the Vitreoscilla hemoglobin gene in Saccharopolyspora spinosa
}

\author{
LUO YuShuang ${ }^{\dagger}$, KOU XiaoXiao ${ }^{\dagger}$, DING XueZhi, HU ShengBiao, TANG Ying, LI WenPing, \\ HUANG Fan, YANG Qi, CHEN HanNa \& XIA LiQiu* \\ State Key Laboratory of Breeding Base of Microbial Molecular Biology, College of Life Science, Hunan Normal University, Changsha 410081, \\ China
}

Received November 18, 2011; accepted December 5, 2011

\begin{abstract}
To promote spinosad biosynthesis by improving the limited oxygen supply during high-density fermentation of Saccharopolyspora spinosa, the open reading frame of the Vitreoscilla hemoglobin gene was placed under the control of the promoter for the erythromycin resistance gene by splicing using overlapping extension PCR. This was cloned into the integrating vector pSET152, yielding the Vitreoscilla hemoglobin gene expression plasmid pSET152EVHB. This was then introduced into $S$. spinosa SP06081 by conjugal transfer, and integrated into the chromosome by site-specific recombination at the integration site $Ф C 31$ on pSET152EVHB. The resultant conjugant, S. spinosa S078-1101, was genetically stable. The integration was further confirmed by PCR and Southern blotting analysis. A carbon monoxide differential spectrum assay showed that active Vitreoscilla hemoglobin was successfully expressed in S. spinosa S078-1101. Fermentation results revealed that expression of the Vitreoscilla hemoglobin gene significantly promoted spinosad biosynthesis under normal oxygen and moderately oxygen-limiting conditions $(P<0.01)$. These findings demonstrate that integrating expression of the Vitreoscilla hemoglobin gene improves oxygen uptake and is an effective means for the genetic improvement of $S$. spinosa fermentation.
\end{abstract}

\section{Saccharopolyspora spinosa, spinosad, Vitreoscilla hemoglobin, integrating vector, homologous recombination}

Citation: Luo Y S, Kou X X, Ding X Z, et al. Promotion of spinosad biosynthesis by chromosomal integration of the Vitreoscilla hemoglobin gene in Saccharopolyspora spinosa. Sci China Life Sci, 2012, 55: 172-180, doi: 10.1007/s11427-012-4276-0

The Vitreoscilla hemoglobin gene $(v g b)$ is located in the chromosomes of Vitreoscilla stercoraria, a strict aerobic gram-negative filamentous bacterium. Upon gene transcription, $v g b$ is induced to synthesize a soluble heme protein called Vitreoscilla hemoglobin ( $\mathrm{VHb}$ ) in relatively large quantities when the strain is grown under hypoxic conditions, thereby satisfying the demand for dissolved oxygen. Originally, $\mathrm{VHb}$ was recognized as a "cytochrome $o$ " with terminal oxidase activity [1]. Spectroscopic analysis revealed that $\mathrm{VHb}$ shared similar oxygen binding kinetics with myoglobin and hemoglobin, and its transition among three states (reduced form, oxidized form and oxygenated

$\dagger$ Contributed equally to this work

*Corresponding author (email: xialq@ @unnu.edu.cn) hemoglobin) depended on the concentration of dissolved oxygen present [2]. Ultramicroscopic structure analysis of cells containing $\mathrm{VHb}$ indicated that it is located in the cytoplasm and is concentrated near the periphery of the cytosolic face of the cell membrane [3]. Early research on the mechanism of $\mathrm{VHb}$ action demonstrated that under hypoxic growth conditions it could capture oxygen and facilitate its transfer to the respiratory membranes by interacting with terminal oxidase, thereby enabling cells to adapt to the hypoxic environment [4]. Recent research on the metabolic regulation and proteomics of $\mathrm{VHb}$ has shown it also has peroxidase activity [5]. Its expression can regulate cells physiological function, eliminate unfavorable effects of by-products such as organic acid production during fermentation $[6,7]$ and regulate the energy and metabolism of cen- 
tral intermediates $[8,9]$. VHb has become a versatile tool in high-density fermentation of micro-organisms susceptible to oxygen supply [10,11]. Recent studies of VHb applications include: (i) promoting the biosyntheses of biochemical precursors (such as Dihydroxyacetone) [12-15]; (ii) improving bioremediation (improving desulfidations in Rhodococcus erythropolis) [16]; (iii) enhancing the production of important enzymes (such as D-amino acid oxidase) [17,18]; (iv) improving the biosyntheses of antibiotics and biopesticides $[19,20]$, and (v) promoting the production of biopolymer materials (such as poly- $\gamma$-glutamic acid) [21,22].

Spinosyns are secondary metabolites produced from the aerobic fermentation of $S$. spinosa. The spinosyns are members of a new class of polyketide-derived macrolides effective against a broad range of insect pests. Originally, they were designated as A83543 factor [23]. The most active and abundant components of the spinosyn family of compounds are spinosyn A and spinosyn D (spinosad). Previous research showed that spinosad has rapid contact and ingestion toxicity to insects. It can kill susceptible insects such as Lepidoptera and Thysanoptera by causing rapid excitation of the insect nervous system, probably through binding and interacting with the nicotin acetylcholine and $\gamma$-amino butyric acid receptors [24]. Importantly, this new class of insecticides showed little or no effect on a broad range of non-target insects and mammals [25]. To date, no other class of product has been found to affect the insect nervous system with the same mode of action and no cross-resistance to spinosad has been reported [26]. Spinosad is considered to be a promising biopesticide worldwide and has been widely used in agriculture as a potent insect control agent and animal health product because of its high efficiency against target insects and environment-friendly characteristics.

However, spinosad levels in wild type $S$. spinosa are low, and therefore considerable interest has been shown in identifying ways to improve its yield. Previously reported methods to improve $S$. spinosa spinosad levels include classic mutagenesis and rational selection [27], protoplast regeneration [28], intergeneric protoplast fusion [29], and duplication of the genes involved in spinosad biosynthesis [30]. S. spinosa has a filamentous growth and used fatty acid as precursor for spinosad biosynthesis, certain amount oil need to be added during fermentation. This results in a viscous culture and a consequent shortage of oxygen, which is one of the limiting thresholds of spinosad production. In this study, we attempted to improve spinosad biosynthesis through enhancing the oxygen supply during high-density fermentation by expression of VHb in S. spinosa.

\section{Materials and methods}

\subsection{Bacterial strains, plasmids and primers}

Bacterial strains, plasmids and primers used in this study are listed in Table 1.

\subsection{Media and cultivation conditions}

All E. coli strains were grown in Luria-Bertani (LB) medium or TY liquid medium [31]. Single clone or $1 \%$ spawn preservation was inoculated into $10 \mathrm{~mL}$ LB medium supplemented with corresponding antibiotics and incubated at $37^{\circ} \mathrm{C}$ with shaking at $200 \mathrm{r} \mathrm{min}^{-1}$ overnight. Seed medium CSM (tryptic soy broth $30 \mathrm{~g} \mathrm{~L}^{-1}$, yeast extract $3 \mathrm{~g} \mathrm{~L}^{-1}$, glucose $5 \mathrm{~g} \mathrm{~L}^{-1}$, maltose $4 \mathrm{~g} \mathrm{~L}^{-1}$ ) was used for the activation of S. spinosa. $0.5 \mathrm{~mL}$ of the bacteria stored in glycerol (stored at $-80^{\circ} \mathrm{C}$ ) was inoculated into $250 \mathrm{~mL}$-flasks containing 20 $\mathrm{mL}$ CSM. Five glass beads $(\sim 5 \mathrm{~mm})$ were added to each flask and incubated at $30^{\circ} \mathrm{C}$ with shaking at $300 \mathrm{r} \mathrm{min}^{-1}$ for $48 \mathrm{~h}$. R6 and BHI (brain heart infusion) solid medium [32] was used for conjugation between $E$. coli and S. spinosa. The fermentation medium and cultivation conditions of $S$. spinosa were previously described [28].

\subsection{Treatment with enzymes, reagents and antibiotics}

LA Taq DNA polymerase, restriction endonuclease, T4 DNA ligase, and agarose gel DNA extraction kits were purchased from Takara Biotechnology Co., Ltd. (Dalian). PCR primers were synthesized by Sangon Biotech Co., Ltd. (Shanghai). Tryptone and yeast extract were purchased from Oxiod. TSB and BHI were purchased from Difco. Digoxin labeling and detection kit were purchased from Roche. Other reagents (analytical grade or chromatographic grade) were purchased from China National Medicines Corporation Ltd. Apramycin (Apr, $50 \mathrm{mg} \mathrm{L}^{-1}$ ), ampicillin (Amp, 50 $\mathrm{mg} \mathrm{\textrm {L } ^ { - 1 }}$ ), chloramphenicol $\left(\mathrm{Cm}, 25 \mathrm{mg} \mathrm{L}^{-1}\right)$, tetracycline (Tet, $25 \mathrm{mg} \mathrm{L}^{-1}$ ), kanamycin (Kan, $50 \mathrm{mg} \mathrm{L}^{-1}$ ), and nalidixic acid (NA, $25 \mathrm{mg} \mathrm{L}^{-1}$ ) antibiotics were purchased from Sigma.

\subsection{Basic operation of gene technology}

Preparation of E. coli competent cells, plasmid extraction, restriction enzyme digestion, ligation, transformation, PCR, electrophoresis and Southern blotting were performed according to Molecular Cloning: A Laboratory Manual [31]. Genomic DNA extraction of S. erythraea and S. spinosa was performed according to Practical Streptomyces Genetics [33]. All PCR products were ligated into pMD18-T vector and analyzed by restriction enzyme digestion. Positive clones were sequenced by Sangon Biotech Co., Ltd. (Shanghai, China).

\subsection{Construction of the integrating vector pSET152- EVHB}

The promoter of erythromycin resistance gene $\left(P_{\text {ermE }}\right)$ was 
amplified from the genomic DNA of $S$. erythraea. The primers, P1 and P2, were designed according to the sequences published in GenBank (gi: 152688). The EcoR I restriction site was introduced into the $5^{\prime}$ end of $\mathrm{P} 1$ and the mutation site of CAGCAC was introduced into P2. The PCR was carried out in a volume of $50 \mu \mathrm{L}$ containing $16.8 \mu \mathrm{L} \mathrm{ddH}_{2} \mathrm{O}$, $25 \mu \mathrm{L} 2 \times$ GC buffer, $2 \mu \mathrm{L} 10 \mathrm{mmol} \mathrm{L}^{-1} \mathrm{dNTP}, 2 \mu \mathrm{L} \mathrm{P} 1,2$ $\mu \mathrm{L} \mathrm{P} 2,2 \mu \mathrm{L}$ DNA template and $0.2 \mu \mathrm{L}$ LA PCR Taq DNA polymerase. The PCR was conducted as follows: denaturation at $94^{\circ} \mathrm{C}$ for $2 \mathrm{~min}$ followed by 28 cycles of $94^{\circ} \mathrm{C}$ for 30 $\mathrm{s}, 60^{\circ} \mathrm{C}$ for $30 \mathrm{~s}, 72^{\circ} \mathrm{C}$ for $30 \mathrm{~s}$, and terminated by incubation at $72^{\circ} \mathrm{C}$ for $5 \mathrm{~min}$. The open reading frame (ORF) of $v g b$ was amplified from the plasmid pRK404-VHb. The primers, P3 and P4, were designed according to the sequences published in GenBank (gi: 155317). The Xba I restriction site was introduced into the $5^{\prime}$ end of $\mathrm{P} 4$ and the mutation site of GTGCTG was introduced into P3. The PCR was carried out in a volume of $50 \mu \mathrm{L}$ containing $35.5 \mu \mathrm{L}$ $\mathrm{ddH}_{2} \mathrm{O}, 5 \mu \mathrm{L} 10 \times$ buffer, $3 \mu \mathrm{L} 2.5 \mathrm{mmol} \mathrm{L}^{-1}$ dNTP, $2 \mu \mathrm{L} \mathrm{P}$, $2 \mu \mathrm{L} \mathrm{P} 4,2 \mu \mathrm{L}$ template and $0.5 \mu \mathrm{L}$ Cas Taq polymerase. The PCR was conducted as follows: denaturation at $94^{\circ} \mathrm{C}$ for $2 \mathrm{~min}$ followed by 28 cycles of $94^{\circ} \mathrm{C}$ for $30 \mathrm{~s}, 55^{\circ} \mathrm{C}$ for $30 \mathrm{~s}$ and $72^{\circ} \mathrm{C}$ for $1 \mathrm{~min}$, and terminated by incubation at $72^{\circ} \mathrm{C}$ for $5 \mathrm{~min}$. The ORF of $v g b$ was placed under control of the $P_{\text {erme }}$ promoter by splicing using an overlapping extension PCR (SOE-PCR), using P1 and P4 as primers and the mixture of $P_{\text {erme }}$ and $v g b$ PCR product as a template. The sequence of the $P_{\text {erme }}-v g b$ cassette was confirmed by TA-colony and DNA sequencing. The integrating vector pSET152EVHB was constructed by placing the $P_{\text {erme }}-v g b$ cassette between the EcoR I and Xba I sites in pSET152.

\subsection{Construction of recombinant $S$. spinosa $\mathrm{S078-1101}$}

The plasmid pSET152EVHB was transformed into $E$. coli ET12567 (pUZ8002) competent cells and the transformants were selected for Apr, $\mathrm{Cm}$ and Kan resistance. The positive E. coli ET12567 (pUZ8002, pSET152EVHB) transformants were confirmed by enzyme digestion after plasmid extraction. E. coli-S. spinosa conjugation was conducted as previously described [32,34] with minor modifications. The recipient stock of S. spinosa SP06081 was cultured in CSM broth, and after $48 \mathrm{~h}$ growth, mycelia were ground with a glass homogenizer. They were then transferred with $10 \%$ of the inoculation into TSB broth in an Erlenmeyer flask and placed on a rocker $\left(300 \mathrm{r} \mathrm{min}^{-1}, 30^{\circ} \mathrm{C}\right)$ for $16 \mathrm{~h}$. After $16 \mathrm{~h}$ the culture was transferred into TSB broth with $25 \%$ of the inoculation, and after $6 \mathrm{~h}$ growth, cells were collected and resuspended in $2 \mathrm{~mL}$ TSB. Meanwhile, the overnightcultured donor bacterium E. coli ET12567 (pUZ8002, pSET152EVHB) was washed twice with TSB to remove residual antibiotics and resuspended in $5 \mathrm{~mL}$ TSB. The donor-recipient (E. coli-S. spinosa) was mixed in the ratio 1:3 $(250 \mu \mathrm{L}: 750 \mu \mathrm{L})$ and added to a sterile centrifuge tube. Then $1 \mathrm{~mL}$ of the mixture was plated on $\mathrm{R} 6$ medium and placed in an ultra clean cabinet for 30 min to be fully absorbed. The conjunction plates were inverted and incubated at $30^{\circ} \mathrm{C}$ for $16 \mathrm{~h}$, then overlaid with Apr and NA to a final concentration of 50 and $25 \mu \mathrm{g} \mathrm{mL} \mathrm{m}^{-1}$ respectively. A single colony on the conjunction plates was selected after 10-14 d culture and inoculated on a BHI plate containing Apr and NA. After 3-4 d growth, partial mycelia of the colonies were transferred into $15 \mathrm{~mL}$ TSB containing $50 \mu \mathrm{g} \mathrm{mL}$ Apr and $25 \mu \mathrm{g} \mathrm{mL}^{-1} \mathrm{NA}$ in a $250 \mathrm{~mL}$ Erlenmeyer flask, and stirred for $3-4 \mathrm{~d}$ at $30^{\circ} \mathrm{C}$. The positive conjugants, named $S$. spinosa S078-1101, were confirmed by PCR amplification of the $A p r$ and $v g b$ gene, and then preserved at $-80^{\circ} \mathrm{C}$ for subsequent analysis.

\subsection{Analysis methods}

\subsubsection{Determination of $\mathrm{VHb}$ biological activity in recom- binant $S$. spinosa}

Carbon monoxide (CO) differential spectrum assay was used to detect VHb biological activity [35]. The mycelia were collected after $5 \mathrm{~d}$ growth in fermentation medium, washed twice with pre-cooling buffer $(10 \mathrm{mmol}$ Tris- $\mathrm{HCl}$, pH 7.0, $60 \mathrm{mmol} \mathrm{NH}{ }_{4} \mathrm{Cl}, 10 \mathrm{mmol} \mathrm{CH}_{3} \mathrm{COOMg}, 1 \mathrm{mmol}$ DTT, $1 \mathrm{mmol}$ phenylmethanesulfonyl fluoride), centrifuged at $4^{\circ} \mathrm{C}$ and resuspended in $10 \mathrm{~mL}$ buffer. Cells were then placed into an ice water mixture and broken into pieces by means of sonication three times $(30$ cycles at $100 \mathrm{~W}$ power, ultrasound for $5 \mathrm{~s}$ with a $15 \mathrm{~s}$ interval). After centrifugation at $3000 \mathrm{r} \mathrm{min}^{-1}$ below $4^{\circ} \mathrm{C}, 0.4 \mathrm{~g}$ sodium dithionite was added to the supernatant, until a saturated concentration was reached. Then the supernatant was divided into two after being reduced at room temperature for 20-30 min: one part was directly poured into a reference cell, and the other was exposed to $\mathrm{CO}$ for $3 \mathrm{~min}$ and placed without shaking in the dark for 10-15 min, before being poured into a detector cell. The spectral scan was performed between 400 and $500 \mathrm{~nm}$.

\subsubsection{Influence of VHb gene expression on the growth of S. spinosa}

The $A_{600}$ value was used to analyze the growth of $S$. spinosa in CSM medium. The bacterial nucleic acid value was applied to determine indirectly the biomass of S. spinosa in the fermentation medium [36]. Each experiment was repeated three times.

\subsubsection{Comparative analysis of spinosad yield between the SP06081 and S078-1101 strains under different dissolved oxygen conditions}

Fermentation for spinosad production was run for $9 \mathrm{~d}$ in a humidified rotary shaker incubator (NBS INNOVO 4900, USA) at $30^{\circ} \mathrm{C}$ and $80 \%$ relative humidity. The ÄKTA Purifier10 (GE Healthcare, USA) high-pressure liquid chromatography (HPLC) system was used for the analysis of spinosad yield. $1 \mathrm{~mL}$ fermentation broth was extracted with 1 
$\mathrm{mL}$ of methanol for $8-10 \mathrm{~h}$ at $30^{\circ} \mathrm{C}$. Methanol extracts were collected by centrifugation at $10000 \mathrm{r} \mathrm{min}^{-1}$ for $15 \mathrm{~min}$. After filtration through $0.22 \mu \mathrm{m}$ Millipore filters, the supernatants $(10 \mu \mathrm{L})$ were loaded onto a C18 column (AQ12S05-1546WT, $150 \mathrm{~mm} \times 4.6 \mathrm{~mm}$ ID, S-5 $\mu \mathrm{m}, 12 \mathrm{~nm}$ ) then eluted with methanol/acetonitrile/2\% aqueous ammonium acetate $(\mathrm{v} / \mathrm{v} / \mathrm{v}=45: 45: 10)$ at $1.5 \mathrm{~mL} \mathrm{~min}^{-1}$. The detection wavelength was $250 \mathrm{~nm}$. A single point external standard method was used for the quantitative analysis of spinosad in HP/C-900 chromatography working station. Three biological replicates were performed for each group experiment, and the data obtained were analyzed for ANOVA using SPSS 15.0 software package and the results were expressed as the mean $\pm \mathrm{SD}$.

\subsection{Genetic stability analysis of $S$. spinosa $\mathrm{S078-1101}$}

The stock S078-1101 strain stored at $-80^{\circ} \mathrm{C}$ was cultured in CSM broth without antibiotics for $48 \mathrm{~h}$, and then the cells were plated on R6 medium without antibiotics after gradient dilution and incubated for $5-7 \mathrm{~d}$ at $30^{\circ} \mathrm{C}$. One hundred strains were selected and inoculated on R6 plates containing Apr (50 mg L ${ }^{-1}$ ), and the number of colonies with antibiotic resistance was counted. Then 20 strains were randomly selected from these resistant clones and transferred into CSM broth, and PCR amplification of the $v g b$ gene from the strain cultures was performed after $48 \mathrm{~h}$ growth. Meanwhile, the $48 \mathrm{~h}$ old cultures were transferred into fermentation medium without antibiotics, and the spinosad yields were analyzed by HPLC after $9 \mathrm{~d}$ fermentation. After five passages by this means, the genetic stability of the recombinant strain was investigated by comparative analysis of the spinosad yields between generations, taking the spinosad yield of the first generation of the recombinant strain as $100 \%$.

\section{Results}

\subsection{Construction of the integrating vector pSET152- EVHB}

The 311-bp $P_{\text {erme }}$ promoter fragment was amplified with the primer pair P1 and P2 using the genome from S. erythraea as a template. The 603-bp $v g b$ gene was amplified with the primer pair P3 and P4 using the plasmid pRK404-VHb as a template. The $0.9 \mathrm{~kb}$ chimeric gene, in which the $v g b$ gene was under the control of the $P_{\text {ermE }}$ promoter was generated by SOE-PCR with the primer pair P1 and P4 (Figure 1A). DNA sequencing of the chimeric gene showed that the start codon of the $v g b$ gene was successfully changed from ATG to GTG while the second codon was changed from TTA to CTG because of the introduction of the mutation site in primers P2 and P3 (Table 1). The chimeric gene was then cloned into pSET152 to generate the final integrating vector pSET152EVHB (Figure 1C) which has the following features: site specific reorganization system int/attP encoded by Streptomyces-phage $\Phi C 31$, which can be integrated into the $a t t B$ site of the $S$. spinosa chromosome; apramycin resistance gene $\operatorname{aac} 3(\mathrm{IV})$; conjugational transfer starting site (oriT); and $v g b$ gene under control of the $P_{\text {ermE }}$ promoter. Two bands ( 5.5 and $0.9 \mathrm{~kb}$ ) were observed by double digestion of pSET152EVHB by EcoR I/Xba I (Figure 1B). The fragments accorded with the predicted DNA digestion fragment sizes, which indicated that the integrating vector was successfully constructed.

\subsection{PCR and Southern blotting detection of S. spi- nosa S078-1101}

PCR was used to check the conjugant $S$. spinosa S078-1101. A 750 bp fragment of the apramycin resistance gene was obtained with the primer pair Apr-F and Apr-R. A $0.9 \mathrm{~kb}$
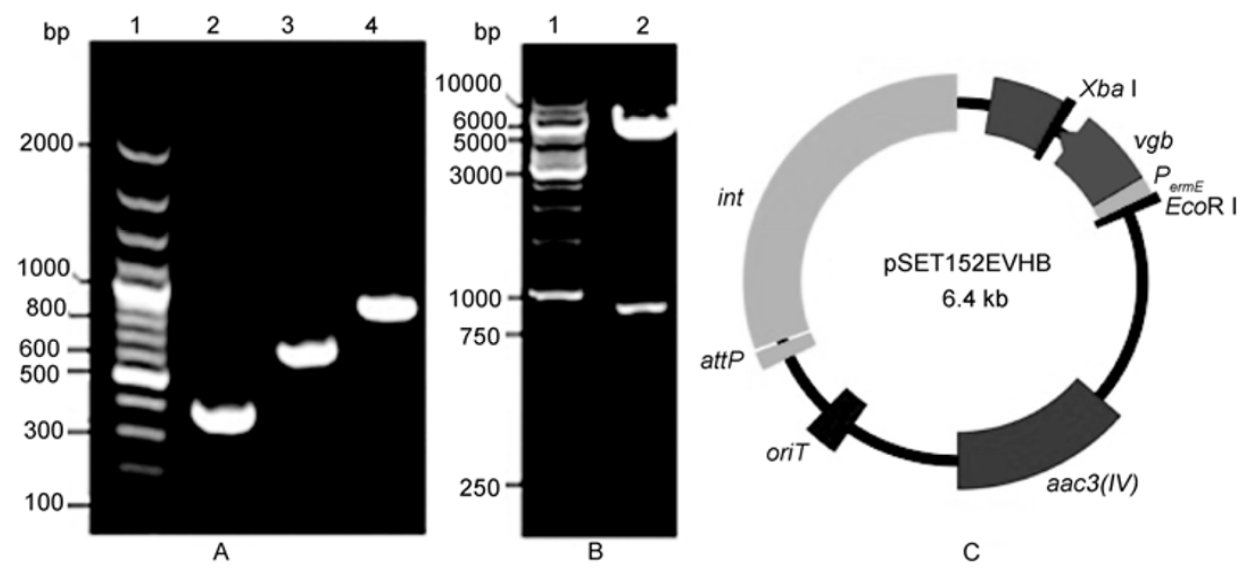

Figure 1 Construction of the integrating vector pSET152EVHB. A, The SOE-PCR products. Lane 1, DNA marker; lane 2, PCR product with primer pair $\mathrm{P} 1 / \mathrm{P} 2$; lane 3, PCR product with primer pair P3/P4; lane 4, PCR product with primer pair P1/P4. B, The EcoR I/Xba I double digestion product of the pSET152EVHB vector. Lane 1, DNA marker; lane 2, pSET152EVHB vector digested with EcoR I and Xba I. C, The profile of pSET152EVHB vector. 
Table 1 Bacterial strains, plasmids and primers used in this study

\begin{tabular}{|c|c|c|}
\hline & Relative description & Source/reference \\
\hline \multicolumn{3}{|l|}{ Strains } \\
\hline E. coli DH5 $\alpha$ & endA1 hsdR17 supE44 thi-1 gyrA relA1 ${ }^{\Delta}\left(\operatorname{lacZYA-argF)} U 169 \mathrm{deoR}\left[{ }^{\Phi} 80 \mathrm{dlac}^{\Delta}(\mathrm{lacZ}) \mathrm{M15}\right]\right.$ & Invitrogen \\
\hline E. coli $\mathrm{ET} 12567(\mathrm{pUZ8002)}$ & $\begin{array}{l}\text { supE44 hsdS20 }\left(r-{ }_{B} m-{ }_{B}\right) \text { ara-14 proA2 lacY galK2 rpsL20 xyl-5 mtl-1 dam-dcm- hsdM-, } \\
\mathrm{Cm}^{\mathrm{R}} \operatorname{Kan}^{\mathrm{R}}\end{array}$ & $\begin{array}{l}\text { John Innes Centre Prof. M. } \\
\text { J. Bibb [33] }\end{array}$ \\
\hline $\begin{array}{l}\text { Saccharopolyspora ery- } \\
\text { thraea }\end{array}$ & $\begin{array}{l}\text { Wild-type erythromycin-producing strain, containing erythromycin resistance gene promot- } \\
\text { er } P_{\text {ermE }} \text { in its chromosome }\end{array}$ & NRRL2338 \\
\hline S. spinosa SP06081 & Wild-type spinosad-producing strain isolated by our Lab & CCTCCNO: M208034 \\
\hline S. spinosa S078-1101 & Apra $^{\mathrm{R}}$ and $v g b$ integrated to the chromosome of SP06081 at attB site & $\begin{array}{l}\text { This work } \\
\text { CCTCCNO: M2011400 }\end{array}$ \\
\hline \multicolumn{3}{|l|}{ Plasmids } \\
\hline pMD18-T vector & $A m p^{R}$, cloning vector & TaKaRa \\
\hline pRK404-VHb & pRK404 harboring whole VHB gene, Tet $^{\mathrm{R}}$ & $\begin{array}{l}\text { China Agricultural Univer- } \\
\text { sity Prof. Wen Ying [10] }\end{array}$ \\
\hline pSET152 & Apra $^{\mathrm{R}}, \Phi C 31$-derived integration vector, pUC18 replicons & $\begin{array}{l}\text { Huazhong Agricultural } \\
\text { University Prof. Tao } \\
\text { MeiFeng [34] }\end{array}$ \\
\hline pSET152EVHB & $v g b$ under the control of $P_{\text {ermE }}$ promoter inserted into pSET152 by EcoR I and $X b a$ I & This work \\
\hline \multicolumn{3}{|l|}{ Primers } \\
\hline P1 & $\boldsymbol{G A A T T C}$ GGT ACC AGC CCG ACC CGA GCA C & This work \\
\hline $\mathrm{P} 2$ & $\begin{array}{l}\text { GAT GTT AAT GGT TTG CTG GTC } \underline{\text { CAGCAC CGC TGG ATC CTA CCA }} \\
\text { P1/P2 were used in } P_{\text {erme }} \text { promoter PCR amplification (the enzyme restriction site in primer } \\
\text { P1 is shown with italic, the underlined bases in primer P2 indicate the mutant sites) }\end{array}$ & This work \\
\hline P3 & 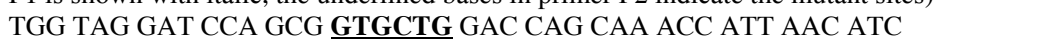 & This work \\
\hline P4 & $\begin{array}{l}\text { TCTAGA ATG CCA AGG CAC ACC TGA AG } \\
\text { P3/P4 were used in } v g b \text { gene PCR amplification (the enzyme restriction site in primer P4 is } \\
\text { shown with italic, the underlined bases in primer P3 indicate the mutant sites) }\end{array}$ & This work \\
\hline Amr-F & GTCCAATACGAATGGCGAAAAGC & This work \\
\hline Amr-R & $\begin{array}{l}\text { ATAACATTCTTCGCATCCCGCC } \\
\text { Apr-F/Apr-R were used in PCR amplification of the apramycin resistant gene aac } 3(I V)\end{array}$ & This work \\
\hline
\end{tabular}

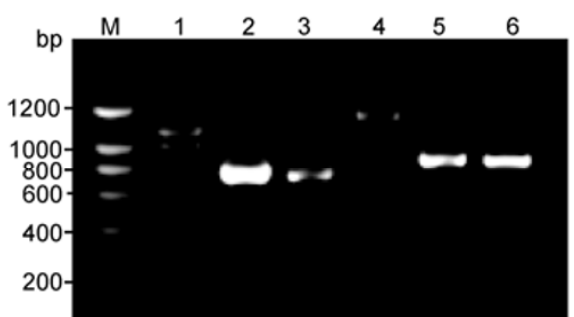

Figure 2 PCR confirmation of the transconjugant $S$. spinosa S078-1101. M, 200 bp DNA ladder; lanes 1-3, PCR product of apramycin resistance gene amplified with primer pair Apr-F/Apr-R; lanes 4-6, PCR product of $v g b$ gene amplified with primer pair P1/P4; lanes 1 and 4 , negative control using SP06081 genome as template for PCR; lanes 2 and 5, positive control using plasmid pSET152EVHB as template for PCR; lanes 3 and 6, the S078-1101 genome was used as a template.

chimeric gene containing the $v g b$ gene and $P_{\text {ermE }}$ promoter was obtained with the primer pair P1 and P4 (Figure 2) and then confirmed by DNA sequencing. It suggested that the $v g b$ gene under the control of $P_{\text {ermE }}$ promoter was integrated into the chromosome of SP06081 together with apramycin resistance gene. When using digoxigenin labeled $v g b$ as a probe, Southern blotting showed that the S078-1101 strain had a $3.2 \mathrm{~kb}$ genomic size hybridization signal, which was absent in the wild type SP06081 strain (Figure 3A and B), and that the fragment size accorded with the predicted di- gestion fragment (Figure 3C). All the results demonstrated that the recombinants S. spinosa S078-1101 was successfully constructed.

\subsection{Detection of biological activity of $\mathrm{VHb}$ in the re- combinant $S$. spinosa}

A carbon monoxide differential spectrum assay was performed using the cell coarse extracting liquid of the $S$. spinosa S078-1101 after $5 \mathrm{~d}$ fermentation. The results showed strong absorption peaks at $420 \mathrm{~nm}$ from the sample of the S078-1101 strain while it was absent in the control sample of the SP06081 strain (Figure 4). This suggested that VHb was expressed in the recombinant strain S078-1101 and could absorb CO to form carboxyhemoglobin, and thereby was biologically active.

\subsection{Effects of VHb expression on the growth and spi- nosad biosynthesis in $S$. spinosa}

Compared with the original SP06081 strain, the S078-1101 strain grew more slowly in CSM. After inoculation, the SP06081 strain reached the exponential phase in $24 \mathrm{~h}$ and the stationary phase in $84 \mathrm{~h}$, while the S078-1101 strain reached the exponential phase in $48 \mathrm{~h}$ and the stationary 

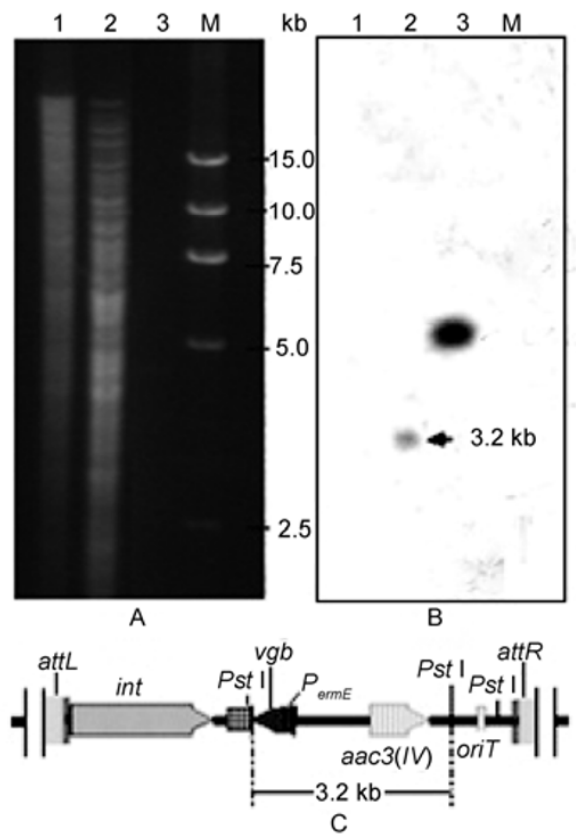

Figure 3 Southern blotting analysis of the transconjugant S. spinosa S078-1101. A, DNA agarose gel electrophoresis before Southern blotting membrane transfer. B, Hybridization of genomic DNA using digoxigenin-labeled $v g b$ probe after Southern blotting membrane transfer. M, DL15000 DNA marker; lanes 1 and 2, S. spinosa SP06081 and S078-1101 genomic fragment digested by $P$ st I respectively, sample loading amount was $10 \mu \mathrm{g}$; lane 3, plasmid pSET152EVHB as a positive control, sample loading amount was $0.5 \mathrm{ng}$. C, The physical maps of pSET152EVHB inserted into the S. spinosa SP06081 chromosome at the attB site.

phase hour in $108 \mathrm{~h}$. The growth rate of the S078-1101 strain during exponential phase was lower than that of the SP06081 strain. However, the difference in growth between the two strains tended to become smaller after the stationary phase, and the cell density of the S078-1101 strain appeared slightly lower than that of the SP06081 strain after $120 \mathrm{~h}$ culture (Figure 5A). Both strains reached maximum biomass after $9 \mathrm{~d}$ culture in fermentation medium. The biomass of the S078-1101 strain was slightly lower than that of the

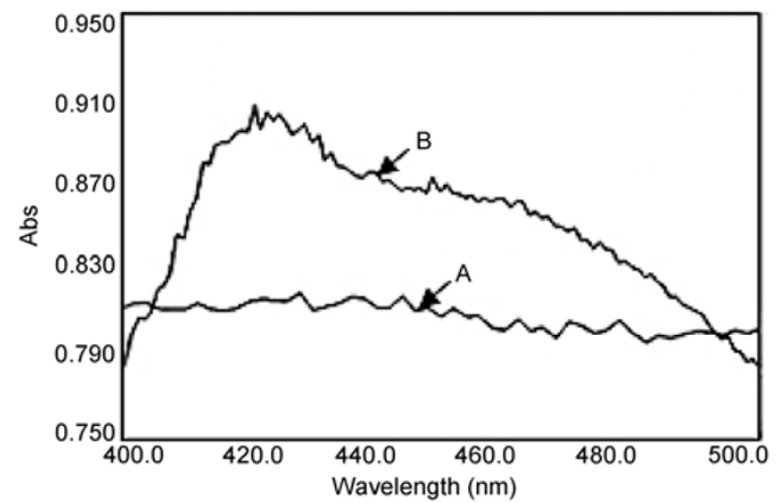

Figure 4 Carbon monoxide differential spectrum assay of VHb. A, $S$. spinosa SP06081. B, S. spinosa $\mathrm{S} 078-1101$.

SP06081 strain during the 5-11 d fermentation, but the difference was not significant $(P>0.05)$ (Figure 5B). These results indicated that integration of the $v g b$ gene into the chromosome of $S$. spinosa inhibited its growth to some extent.

The spinosad yields of the two strains during the fermentation appeared to vary in a similar manner (Figure 5C). Spinosad production was first detected after $5 \mathrm{~d}$ fermentation. Subsequently, it increased sharply and reached maximum yield after $9 \mathrm{~d}$ fermentation, and then decreased. The spinosad yields of the S078-1101 strain were significantly higher than the original strain at $7 \mathrm{~d}$ after fermentation, and the difference in spinosad production between the two strains became significant with the increase of fermentation time $(P<0.01)$. Our present data demonstrated that $\mathrm{VHb}$ expression in $S$. spinosa significantly promoted spinosad biosynthesis.

\subsection{Spinosad yield analysis of the recombinant strain under different dissolved oxygen conditions}

The effects of $v g b$ expression in $S$. spinosa on spinosad bi-
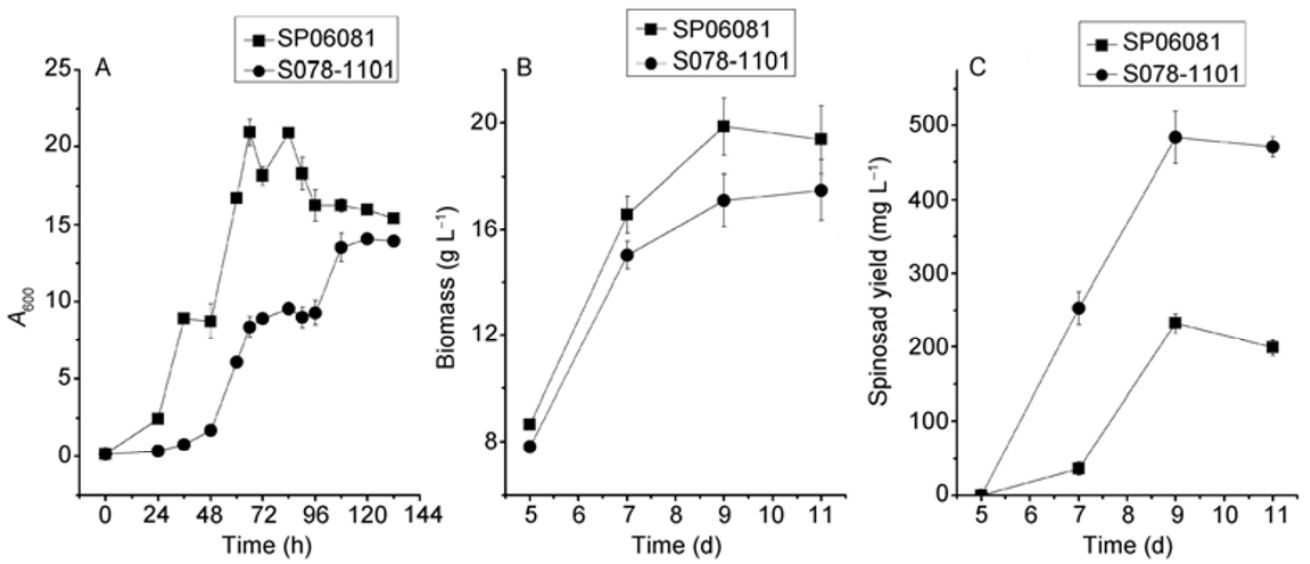

Figure 5 Effects of VHb expression on the growth and spinosad biosynthesis of S. spinosa. A, The growth curve of the S. spinosa SP0681 and S078-1101 cultured in CSM. B, The biomass yields of S. spinosa SP06081 and S078-1101 during fermentation. C, The spinosad yields of S. spinosa SP06081 and S078-1101 during fermentation. 
osynthesis were investigated under different dissolved oxygen conditions, which were simulated by using shake-flask fermentation with different media quantum at different rotation speeds (Table 2). The results showed that the level of dissolved oxygen had a significant influence on spinosad biosynthesis, as the spinosad yields of SP06081 and the recombinant strains decreased markedly with the increase in media quantum or a decrease in rotation speed. Compared with normal oxygen supply conditions, the spinosad yields of the two strains were reduced to more than $50 \%$ under moderate oxygen-limiting supply conditions. However, the spinosad yields of the recombinant strain were significantly increased whether at normal oxygen levels or moderate oxygen-limiting conditions compared with that of the original strain $(P<0.01)$. Moreover, the spinosad yields of the two strains under highly oxygen-limiting conditions decreased more than $97 \%$. There was no significant difference between the two strains $(P>0.05)$ in spinosad biosynthesis although the yields were higher in the recombinant strain compared with the SP06081 strain.

\subsection{Stability of the recombinant strain of $S$. spinosa}

The proportion of cells showing apramycin resistance was determined in cultures grown in the absence of apramycin to investigate the stability of the S078-1101 strain. After five passages, the fraction of colonies which remained apramycin resistant after 5-7 d cultivation in R6 medium without apramycin was greater than $98 \%$ (data not shown). This suggested the $v g b$ expression cassette was stably integrated into the chromosome of $S$. spinosa. Further shake-flask fermentation of the different passages with no antibiotic resistance showed that their relative potency of spinosad production was stable and more than $95 \%$. These results demonstrated that the recombinant strain with chromosomally integrated $v g \mathrm{~b}$ gene was genetically stable.

\section{Discussion}

Although the biosynthetic gene cluster and pathway of spinosad have been elucidated, little is known about the regulation of these genes' expression. It is difficult to improve secondary metabolite production by orienting genetic manipulation of $S$. spinosa. In our previous studies, we iso- lated a spinosad-producing S. spinosa SP06081 strain, but despite its stable heredity, the spinosad yield of SP06081 was lower and the dissolved oxygen supply was too demanding for the fermentative production of spinosad. The positive correlation between the potency against hypoxia and spinosad production was also observed during the traditional genetic improvement of the SP06081 strain. Moreover, differential proteomic analysis of S. spinosa SP06081 and the spinosad-hyperproducing PR2 strain, which was obtained from its protoplast regeneration, demonstrated that a group of proteins involved in anti-oxidant stress was significantly up-regulated in the PR2 strain [37]. For the aforementioned reasons, further investigations on the improvement of oxygen uptake properties of the SP06081 strain were conducted to promote spinosad biosynthesis. Heterologous expression of $\mathrm{VHb}$ has been reported to improve cell growth, protein synthesis, metabolite productivity and nitric oxide detoxification. The strategies applied to $v g b$ gene expression include site-specific integration into the chromosome [19-21], co-expression [14,15,22] and fusion expression [17]. Our original attempt was to express VHb in $S$. spinosa by a replicable vector pJN100-VHb which was constructed by cloning $v g b$ ORF into the $E$. coli/Streptomyces shuttle vector pJN100 [38]. Unfortunately, no positive clones were obtained when pJN100-VHb was transformed into the SP06081 strain, whether by electroporation of mycelia, PEG-mediated protoplast transformation or by conjugation. This may be attributed to the strong host restriction of S. spinosa SP06081, which blocked foreign plasmid duplication. Previous research has indicated there are two bacteriophage $\Phi C 31$ attB sites in the chromosome of $S$. spinosa and that the integration of small fragment DNA at either of the ФC31 attB sites has no influence on spinosad biosynthesis [32]. Thus, the $v g b$ gene was cloned into the ФC31-derived plasmid pSET152 [34], yielding the integrating vector pSET152EVHB, which was then introduced into $S$. spinosa SP06081 by conjugation and integrated into its chromosomes. Despite the lower efficiencies (approximately $10^{-7}$ per recipient) and DNA fragment deletion for conjugative gene transfer in $S$. spinosa, a positive conjugant named S. spinosa S078-1101 was obtained, showing genetic stability and expressing $\mathrm{VHb}$ with biological activity.

The biomass of the recombinant S078-1101 strain

Table 2 Effects of the expression of VHb under different oxygen supply conditions on the spinosad biosynthesis of $S$. spinosa

\begin{tabular}{|c|c|c|c|}
\hline \multirow{2}{*}{ Oxygen supply conditions } & \multirow{2}{*}{ Flask volume/medium volume/rotating speed } & \multicolumn{2}{|c|}{ Spinosad yield $\left(\mathrm{mg} \mathrm{L}^{-1}\right)$} \\
\hline & & SP06081 & S078-1101 \\
\hline Normal oxygen & $300 \mathrm{~mL} / 20 \mathrm{~mL} / 300 \mathrm{r} \mathrm{min}^{-1}$ & $251.1 \pm 4.4^{\mathrm{a})}$ & $466.6 \pm 15.2^{\mathrm{a}), \mathrm{b})}$ \\
\hline Moderately oxygen-limiting & $300 \mathrm{~mL} / 20 \mathrm{~mL} / 240 \mathrm{r} \mathrm{min}^{-1}$ & $152.4 \pm 6.5^{\mathrm{a}, \mathrm{b})}$ & $211.0 \pm 2.8^{\mathrm{a}), \mathrm{b})}$ \\
\hline Highly oxygen-limiting & $300 \mathrm{~mL} / 50 \mathrm{~mL} / 240 \mathrm{r} \mathrm{min}^{-1}$ & $5.3 \pm 1.9^{\mathrm{b})}$ & $12.9 \pm 2.5^{\mathrm{b})}$ \\
\hline
\end{tabular}

a) Compared with SP06081 strain under highly oxygen-limiting supply, $P<0.01$. b) Compared with SP06081 strain under normal oxygen supply, $P<0.01$. Spinosad yield is expressed as the mean \pm SD. 
whether in seed medium or fermentation medium was lower than that of the original strain (Figure 5A and B). However, the spinosad yields of the S078-1101 strain were significantly increased under both normal oxygen and moderate oxygen-limiting conditions compared with that of the SP06081 strain $(P<0.01$; Figure 5C, Table 2). A similar effect of $v g b$ gene expression was previously demonstrated by Brünker et al. [39]. However, our findings were different to those obtained in Streptomyces lincolnensis by Yang et al. [19]. The expression of VHb in S. lincolnensis had no significant influence on the growth and antibiotic production under normal dissolved oxygen conditions, and it promoted an increase in growth and lincomycin yield only under oxygen-limiting conditions. These results are probably due to the different regulation mechanisms in diverse microorganisms under different growth conditions. In addition, no significant differences in biomass between the original strain and the recombinant strain were observed during fermentation under normal oxygen supply conditions, whereas spinosad yields of the recombinant strain notably increased. Microscopic examination also showed no obvious differences in mycelial fragmentation between the two strains. Therefore, the increase of spinosad yield in the S078-1101 strain was probably due to VHb expression, which may improve oxygen utilization by cells, thereby accelerating certain oxygen-requiring rate-limiting steps involved in spinosad production. This would lead to more metabolic flux towards the spinosad biosynthetic pathway. Further investigations are required to elucidate the precise mechanisms of $\mathrm{VHb}$ action and regulation in $S$. spinosa.

The native promoter of $v g b\left(P_{v g b}\right)$ is regulated by dissolved oxygen (DO) concentration in Vitreoscilla and $E$. coli. It is induced at low DO levels (less than $2 \%$ of air saturation) to express soluble hemoglobin, which enables cells to adapt to hypoxic environments. Although $P_{v g b}$ is functional without the need of expensive inducers, it is not directly regulated by dissolved oxygen. Transcriptional activity of the $P_{v g b}$ in E. coli is modulated by two oxygen sensors, ferredoxin-NADP reductase and aerobic respiratory control A protein [40,41]. As $P_{v g b}$ is not functional in most gram-positive bacteria or eukaryotic organisms, various promoter strategies have been adopted by researchers to induce expression of $\mathrm{VHb}$ in heterologous hosts. Suthar et al. [18] used an $\alpha$-amylase promoter $P_{A M Y 1}$ in Schwanniomyces occidentalis; Horng et al. [22] applied $P_{B A D}$ in E. coli; Feng et al. [20] used $P_{\text {luxs }}$ in Bacillus thuringiensis; and Xiong et al. [16] employed $P_{d s z}$ in Rhodococcus erythropolis. In this study, the first and second codons of $v g b$ were mutated to GTG and CTG respectively by site-directed mutagenesis and SOE-PCR. In addition, the $v g b$ ORF was placed under control of the $P_{\text {ermE }}$ promoter, which has been successfully applied to actinomycetic metabolic engineering $[19,42]$. Using this strategy, active VHb was successfully expressed in S. spinosa (Figure 4).

To summarize, the recombinant S078-1101 strain has the following advantages. First, $v g b$ was controlled by a constitutively expressed promoter, thus its expression does not need to be induced. Second, the expression of $v g b$ significantly promoted spinosad biosynthesis in normal oxygen and moderate oxygen-limiting conditions. Third, $v g b$ was stably integrated into the chromosome of S. spinosa, and no significant changes in spinosad production potency were observed after five generations of propagation without antibiotic selection. These results suggest that integrating $v g b$ in $S$. spinosa is an effective means of orientation genetic improvement, by which, the oxygen absorption capacity of $S$. spinosa can be improved to promote spinosad biosynthesis. Moreover, to exploit the potential of spinosad production to a greater degree, our research directions in the future are as follows: (i) integration of $v g b$ into chromosomes of other $S$. spinosa with higher capabilities of spinosad production; and (ii) searching for other strong constitutively expressed promoters which are functional in S. spinosa.

We thank M. J. Bibb from the John Innes Centre, Prof. Tao MeiFeng from Huazhong Agricultural University and Prof. Wen Ying from China Agricultural University for providing some of the vectors and strains used for gene manipulation in this work. This work was supported by the National Basic Research Program of China (Grant Nos. 2012CB722301 and 2011CB111605), the National High Technology Research and Development Project of China (Grant No. 2011AA10A203), and the National Natural Science Foundation of China (Grant No. 31070006).

1 Toshi M, Mande S, Dikshit K. Hemoglobin biosynthesis in Vitreoscilla stercoraria DW: cloning, expression, and characterization of a new homolog of a bacterial globin gene. Appl Environ Microbiol, 1998, 64: 2220-2228

2 Orii Y, Webster D A. Photodissociation of oxygenated cytochrome $o(\mathrm{~s})$ (Vitreoscilla) and kinetic studies of reassociation. J Biol Chem, 1986, 261: 3544-3547

3 Ramandeep H K W, Raje M, Kim K J, et al. Vitreoscilla hemoglobin. Intracellular localization and binding to membranes. J Biol Chem, 2001, 276: 24781-24789

4 Kim K J, Chi P Y, Hwang K W, et al. Study of cytochrome bo function in Vitreoscilla using a cyo-knockout mutant. J Bio Chem, 2000, 128: 49-55

5 Kvist M, Ryabova E S, Nordlander E, et al. An investigation of the peroxidase activity of Vitreoscilla hemoglobin. J Biol Inorg Chem, 2007, 12: 324-334

6 Kim Y J, Sa S O, Chang Y K, et al. Overexpression of Shinorhizobium meliloti hemoprotein in Streptomyces lividans to enhance secondary metabolite production. J Microbiol Biotechnol, 2007, 17: 2066-2070

7 Anand A, Duk B, Singh S, et al. Redox-mediated interactions of $\mathrm{VHb}$ (Vitreoscilla haemoglobin) with OxyR: novel regulation of VHb biosynthesis under oxidative stress. Biochem J, 2010, 426: 271-280

8 Hofmann G, Diano A, Nielsen J. Recombinant bacterial hemoglobin alters metabolism of Aspergillus niger. Metab Eng, 2009, 11: 8-12

9 Isarankura-Na-Ayudhya C, Panpumthong P, Tangkosakul T, et al. Shedding light on the role of Vitreoscilla hemoglobin on cellular catabolic regulation by proteomic analysis. Int J Biol Sci, 2008, 4: 71-80

10 Wen Y, Song Y, Li J L. The effects of Vitreoscilla hemoglobin expression on growth and antibiotic production in Streptomyces cinnamonensis. Chin J Biotech, 2001, 17: 24-28

11 Zhang L, Li Y, Wang Z, et al. Recent developments and future prospects of Vitreoscilla hemoglobin application in metabolic engineering. Biotechnol Adv, 2007, 25: 123-136 
12 Li M, Wu J, Lin J, et al. Expression of Vitreoscilla hemoglobin enhances cell growth and dihydroxyacetone production in Gluconobacter oxydans. Curr Microbiol, 2010, 61: 370-375

13 Kurt A G, Aytan E, Ozer U, et al. Production of L-DOPA and dopamine in recombinant bacteria bearing the Vitreoscilla hemoglobin gene. Biotechnol J, 2009, 4: 1077-1088

14 Chen H, Chu J, Zhang S, et al. Intracellular expression of Vitreoscilla hemoglobin improves S-adenosylmethionine production in a recombinant Pichia pastoris. Appl Microbiol Biotechnol , 2007, 74: 1205-1212

15 Chien L J, Lee C K. Enhanced hyaluronic acid production in Bacillus subtilis by coexpressing bacterial hemoglobin. Biotechnol Prog, 2007, 23: $1017-1022$

16 Xiong X C, Xing J M, Li X, et al. Enhancement of biodesulfurization in two-liquid systems by heterogeneous expression of Vitreoscilla hemoglobin. Appl Environ Microbiol, 2007, 73: 2394-2397

17 Yu H M, Ma X F, Luo H, et al. Fusion expression of $D$-amino acid oxidase from Trignoposis variabilis with maltose binding protein and Vitreoscilla hemoglobin. Chin J Biotech, 2008, 24: 1004-1009

18 Suthar D H, Chattoo B B. Expression of Vitreoscilla hemoglobin enhances growth and levels of $\alpha$-amylase in Schwanniomyces occidentalis. Appl Microbiol Biotechnol, 2006, 72: 94-102

19 Yang H T, Liu R H, He J Y, et al. Cloning of Vitreoscilla hemoglobin gene and its expression in Streptomyces lincolnensis. J Shenyang Pharm Univ, 2009, 26: 657-662

20 Feng L, Chen S W, Sun M, et al. Expression of Vitreoscilla hemoglobin in Bacillus thuringiensis improves the cell density and insecticidal crystal proteins yield. Appl Microbiol Biotechnol, 2007, 74: 390-397

21 Su Y S, Li X, Liu Q Z, et al. Improved poly- $\gamma$-glutamic acid production by chromosomal integration of the Vitreoscilla hemoglobin gene ( $\mathrm{vgb})$ in Bacillus subtilis. Bioresource Technol, 2010, 101: 4733-4736

22 Horng Y T, Chang K C, Chien C C, et al. Enhanced polyhydroxybutyrate (PHB) production via the coexpressed phaCAB and $v g b$ genes controlled by arabinose PBAD promoter in Escherichia coli. Lett Appl Microbiol, 2010, 50: 158-167

23 Mertz F P, Yao R C. Actinomadura fibrosa sp. nov. isolated from soil. Int J Syst Bacteriol, 1990, 40: 28-33

24 Millar N S, Denholm I. Nicotinic acetylcholine receptors: targets for commercially important insecticides. Invert Neurosci, 2007, 7: 53-66

25 Cleveland C B, Bormett G A, Saunders D G, et al. Environmental fate of spinosad. 1. Dissipation and degradation in aqueous systems. J Agric Food Chem, 2002, 50: 3244-3256

26 Mota-Sanchez D, Hollingworth R M, Grafius E J, et al. Resistance and cross-resistance to neonicotinoid insecticides and spinosad in the Colorado potato beetle, Leptinotarsa decemlineata (Say)(Coleoptera: Chrysomelidae). Pest Manag Sci, 2006, 62: 30-37

27 Jin $\mathrm{Z}$, Wu J, Zhang $\mathrm{Y}$, et al. Improvement of spinosad producing Saccharopolyspora spinosa by rational screening. J Zhejiang Univ SCIENCE A, 2006, 7: 366-370
28 Luo Y S, Ding X Z, Xia L Q, et al. Conditions for protoplast preparation of spinosyn-producing strain and the physiological properties of protoplast-regenerated strains. Chin J Biotech, 2009, 25: 360-367

29 Wang C, Zhang X, Chen Z, et al. Strain construction for enhanced production of spinosad via intergeneric protoplast fusion. Can J Microbiol, 2009, 55: 1070-1075

30 Tang Y, Xia L, Ding X, et al. Molecular cloning and overexpression of partial spinosyn biosynthetic gene cluster in Saccharopolyspora spinosa enhances spinosad production. FEMS Microbiol Lett, 2011, 325: 22-29

31 Sambrook J, Fritsch E F, Maniatis T (author), et al. Molecular Cloning: A Laboratory Manual. 2nd ed. Beijing: Science Press, 1992. 43-370

32 Matsushima P, Broughton M C, Turner J R, et al. Conjugal transfer of cosmid DNA from Escherichia coli to Saccharopolyspora spinosa: effects of chromosomal insertions on macrolide A83543 production. Gene, 1994, 146: 39-45

33 Kieser T, Bibb M J, Buttner M J, et al. Practical Streptomyces Genetics. Norwich: The John Innes Foundation, Colney, 2000. 161-211

34 Bierman M, Logan R, O'Brien K, et al. Plasmid cloning vectors for the conjugal transfer of DNA from Escherichia coli to Streptomyces spp. Gene, 1992, 116: 43-49

35 Feng L. Effects of the expression of Vitreoscilla hemoglobin gene in Bacillus thuringiensis on its fermentative characters. Dissertation for Doctoral Degree. Wuhan: Huazhong Agriculture University, 2006

36 Yuan H S, Li S N, Zhu B C, et al. Studies on mycelia content measuring of Penicillium chrysogenum in fermentation. J Agricult Univ Hebei, 2007, 30: 83-86

37 Luo Y, Ding X, Xia L, et al. Comparative proteomic analysis of Saccharopolyspora spinosa SP06081 and PR2 strains reveals the differentially expressed proteins correlated with the increase of spinosad yield. Proteome Sci, 2011, 9: 40

38 Nikodinovic J, Priestley N D. A second generation snp-derived Escherichia coli-Streptomyces shuttle expression vector that is generally transferable by conjugation. Plasmid , 2006, 56: 223-227

39 Brünker P, Minas W, Kallio P T, et al. Genetic engineering of an industrial strain of Saccharopolyspora erythraea for stable expression of the Vitreoscilla haemoglobin gene (vhb). Microbiology, 1998, 144: 2441-2448

40 Yang J, Webster D A, Stark B C. ArcA works with Fnr as a positive regulator of Vitreoscilla (bacterial) hemoglobin gene expression in Escherichia coli. Microbiol Res, 2005, 160: 405-415

41 Tsai P S, Kallio P T, Bailey J E. Fnr, a global transcriptional regulator of Escherichia coli, activates the Vitreoscilla hemoglobin (VHb) promoter and intracellular $\mathrm{VHb}$ expression increases cytochrome $d$ promoter activity. Biotechnol Prog, 1995, 11: 288-293

42 Priscila G, Fernández F J, Absalón A E, et al. Expression of the bacterial hemoglobin gene from Vitreoscilla stercoraria increases rifamycin B production in Amycolatopsis mediterranei. J Biosic Bioeng, 2008, 106: 493-497

Open Access This article is distributed under the terms of the Creative Commons Attribution License which permits any use, distribution, and reproduction in any medium, provided the original author(s) and source are credited. 